\title{
Assessment of Genetic Diversity and Character Associations for Yield and Its Traits in Bread Wheat (Triticum aestivum L.)
}

\author{
Anuj Kumar, Pooran Chand ${ }^{1}$, Ravi Singh Thapa, Tejbir Singh
}

10.18805/IJARe.A-5686

\begin{abstract}
Background: Wheat (Triticum aestivum L.) an important self-pollinated and hexaploid $(2 n=6 x=42)$ cereal crop belongs to the grass family Gramineae (Poaceae). With the gradual increase in human population, there is a substantial increase in the demands for food requirements. Hence, increasing the wheat production is an important goal to overcome the demand of food. The only alternative is to increase productivity by better crop management techniques and introduction of high yielding varieties. The current study aimed to study the genetic diversity in wheat genotypes for further selection and utilization in breeding programmes and identification of transgressive segregants for genetic improvement in wheat crop.

Methods: In the field investigation during 2017-2019, forty genotypes were evaluated at research farm of Department of Genetics and Plant Breeding, Kisan P.G. College, Simbhaoli, Hapur (U.P). The observations were recorded on five randomly selected competitive plants from each genotype in each replication and recorded data from each replication was subjected to statistical analysis.

Result: Significant differences were observed for all the characters studied in both environments (early and late). Highest GCV and PCV were recorded for flag leaf area, number of tillers per plant and grain yield in both environments. Plant height, days to $50 \%$ heading and grain yield in early sowing and for plant height, gluten content and grain yield exhibited high heritability estimates in late sowing. Biological yield and harvest index showed positive and significant association with grain yield under both environments. Biological yield and harvest index have positive and direct effect on grain yield in both environments. Forty genotypes were grouped into seven clusters in early sowing and six clusters in late sowing. Maximum inter cluster distance was observed between clusters VI and IV in early sowing and between cluster III and II in Late sowing. Genotypes PBW-34 showed wide genetic diversity in both the environments (early and late sowing). Based on the divergence studies it is suggested that maximum heterosis and good recombinants could be obtained in crosses between the genotypes of clusters which showed highest inter cluster distance and these genotypes can be utilized in crop improvement programmes.
\end{abstract}

Key words: ANOVA, GCV, Genetic divergence, Heritability, PCV.

\section{INTRODUCTION}

Wheat (Triticum aestivum L.) is a crop of temperate region and the most important and second largest grown cereal crop in India after rice and plays a vital role in food and nutritional security. Currently it is grown on a large scale in the tropical and subtropical regions of the world (Onwueme and Sinha, 1999). After rice, wheat is the major staple food in the world and considered as King of cereals. It provides food to $55 \%$ of the world population contributing $20 \%$ of the food calories and occupies a unique position as used for the preparation of wide range of food stuffs. In India wheat occupies an area of 31.05 million hectare with production of about 107.18 million tons during 2019-20 (Anonymous, 2020). It is a challenging task for breeders to enhance the present level of production to feed the growing population of the country as compared to the present day requirements. There is no possibility to increase the area under production, thereby evolving superior varieties and better management of crop production is the only alternate to cope with the increasing demand of food.

To overcome food shortage and to feed the increasing population, it is important to increase per unit yield through the development of high yielding and relatively stable wheat genotypes for diverse environments. For the successful breeding program, the presence of genetic diversity play a
Department of Genetics and Plant Breeding, Kisan PG College, Simbhaoli-245 207, Hapur, Uttar Pradesh, India.

1Department of Genetics and Plant Breeding, Sardar Vallabhbhai Patel University of Agriculture and Technology, Meerut-250 110, Uttar Pradesh, India.

Corresponding Author: Tejbir Singh, Department of Genetics and Plant Breeding, Kisan PG College, Simbhaoli-245 207, Hapur, Uttar Pradesh, India. Email: drtejbir@yahoo.com

How to cite this article: Kumar, A., Chand, P., Thapa, R.S. and Singh, T. (2021). Assessment of Genetic Diversity and Character Associations for Yield and Its Traits in Bread Wheat (Triticum aestivum L.). Indian Journal of Agricultural Research. 55(6): 695701. DOI: $10.18805 /$ IJARe.A-5686.

Submitted: 22-09-2020 Accepted: 16-12-2020 Online: 11-02-2021

vital role for genetic improvement of the crops and it is very important factor for any hybridization program aiming at genetic improvement of yield especially in self pollinated crops (Joshi and Dhawan, 1966). Genetic diversity in any crop determine their potential for improvement in yield and quality and hence their use in breeding. Keeping the above in view, in the present study an attempt has been made to assess the genetic diversity and character association for yield and its traits in bread wheat (Triticum aestivum L.). 
Grain yield is the quantitative traits which is outcome of several contributing factor affecting grain yield directly or indirectly. Therefore alone yield cannot be considered for selection of desirable genotypes other yield components should be considered in selection. So the information of mutual association between yield and yield components is necessary for the effective utilization of the genetic stock in the crop improvements. The path coefficient analysis partition the correlation coefficient components into direct and indirect effect and measure the relative importance of each independent variable to prediction of change in the dependent variable and has been found to give more specific information on the direct and indirect influences of each of the characters upon grain yield and can be used to calculate the quantitative impact on yield for direct and indirect effects caused by one or more components.

\section{MATERIALS AND METHODS}

The experimental material comprised forty wheat genotypes and were evaluated at research farm of Department of Genetics and Plant Breeding Kisan P.G. College, Simbhaoli, Hapur (UP) in randomized block design with three replications in early and late sowing during rabi season 2017-18. The observations were recorded on five randomly selected competitive plants from each genotypes in each replication on twelve quantitative characters viz., days to $50 \%$ heading, days to maturity, plant height $(\mathrm{cm})$, number of productive tillers per plant, number of spikelets per spike, spike length $(\mathrm{cm})$, flag leaf area $\left(\mathrm{cm}^{2}\right), 1000$-grain weight $(\mathrm{g})$, biological yield $(\mathrm{g})$, harvest index $(\%)$, gluten content $(\%)$ and grain yield $(\mathrm{g})$. The mean value of recorded data from each replication was subjected to statistical analysis. Analysis of variance was calculated based on the method suggested by Panse and Sukhatme, 1969. Genotypic coefficient of variation (GCV) and phenotypic coefficient of variation (PCV) was calculated according to the formula suggested by Burton and Devane, 1953. Heritability and genetic advance were calculated through method suggested by Johnson et al., 1955. Genetic divergence analysis was done based on Mahalanobis $D^{2}$ method (1936).

\section{RESULTS AND DISCUSSION}

In the present investigation forty diverse wheat genotypes were studied to assess genetic diversity under two different environments (early sowing and late sowing). The analysis of variance for different characters is presented in Table 1. Highly significant differences was observed among the genotypes for all the characters studied in both the environments (early and late sowing). Significant differences among the genotypes for all characters were reported earlier (Mishra et al., 2019, Chaudhary et al., 2020 and Haydar et al., 2020).

The magnitude of phenotypic coefficient of variation (PCV) was greater than genotypic coefficient of variation (GCV) for all the characters studied indicating vital role of environmental interaction in the expression of the characters. The estimates of GCV and PCV in both the environments (early and late sowing) were high for flag leaf area, number of tillers per plant, grain yield per plant, plant height and spike length (Table 2) in both the environments. Similar results were also reported by Kumari et al., 2017, Kumar et al., 2019 and Ferede and Worede, 2020.

In the early sowing Environment (I) the estimates of heritability were higher for plant height followed by days to $50 \%$ heading, grain yield per plant, flag leaf area, number of spikelet per spike and spike length and moderate for the biological yield, 1000 grain weight, days to maturity and number of tillers per plant. High heritability for these characters was also reported earlier by Gaur, 2019 and Saini et al., 2019. In the Environment II heritability was high for plant height followed by gluten content, grain yield per plant, 1000 grain weight, flag leaf area, biological weight, days to maturity and days to $50 \%$ heading and moderate for harvest index spike length and number of tillers per plant. These results were in accordance with the results of Saini et al., 2019 and Upadhyay et al., 2020. Higher values of genetic advance as percent of mean was recorded for flag leaf area, grain yield per plant, number of tillers per plant and plant height in both environmental (early and late sowing) conditions (Table 2). Similar result was also observed by Gaur, 2019.

Grain yield showed significant and positive correlation with number of tillers per plant, biological yield and harvest index in both the environments (Table 3). Further, the trait grain yield showed significant and positive correlation with spike length (Environment I) and flag leaf area (Environment II). The grain yield also showed significant and negative correlation with days to $50 \%$ heading (Environment I and II) and days to maturity (Environment II). Among the inter se associations the magnitude of correlation coefficient of grain yield with harvest index and biological yield was maximum and positive followed by correlation of spike length with number of spikelets per spike (Table 3 ). Similar results were also observed by Verma et al., 2019, Khanal et al., 2020, Rathod et al., 2020 and Jan et al., 2020.

The path coefficient analysis showed that biological yield and harvest index exhibited maximum positive direct effect on grain yield in both the environments. The number of tillers per plant, spike length and flag leaf area contributed indirectly towards grain yield via biological yield and harvest index (Table 4 and Table 5). Similar results was also observed by Verma et al., 2019, Baye et al., 2020 and Upadhyay, 2020.

The divergence analysis showed that all the forty genotypes were grouped into seven clusters in Environment I and six clusters (Environment II). Maximum number of genotypes was grouped into cluster $\mathrm{V}$ (Environment I) and clusters I (Environment II). Maximum inter cluster distance was observed between clusters VI and IV in Environment I and Cluster III and II in Environment II. Genotypes namely PBW-34, HD-2985, HD-2189, HUW-234 and UP-2485 in 

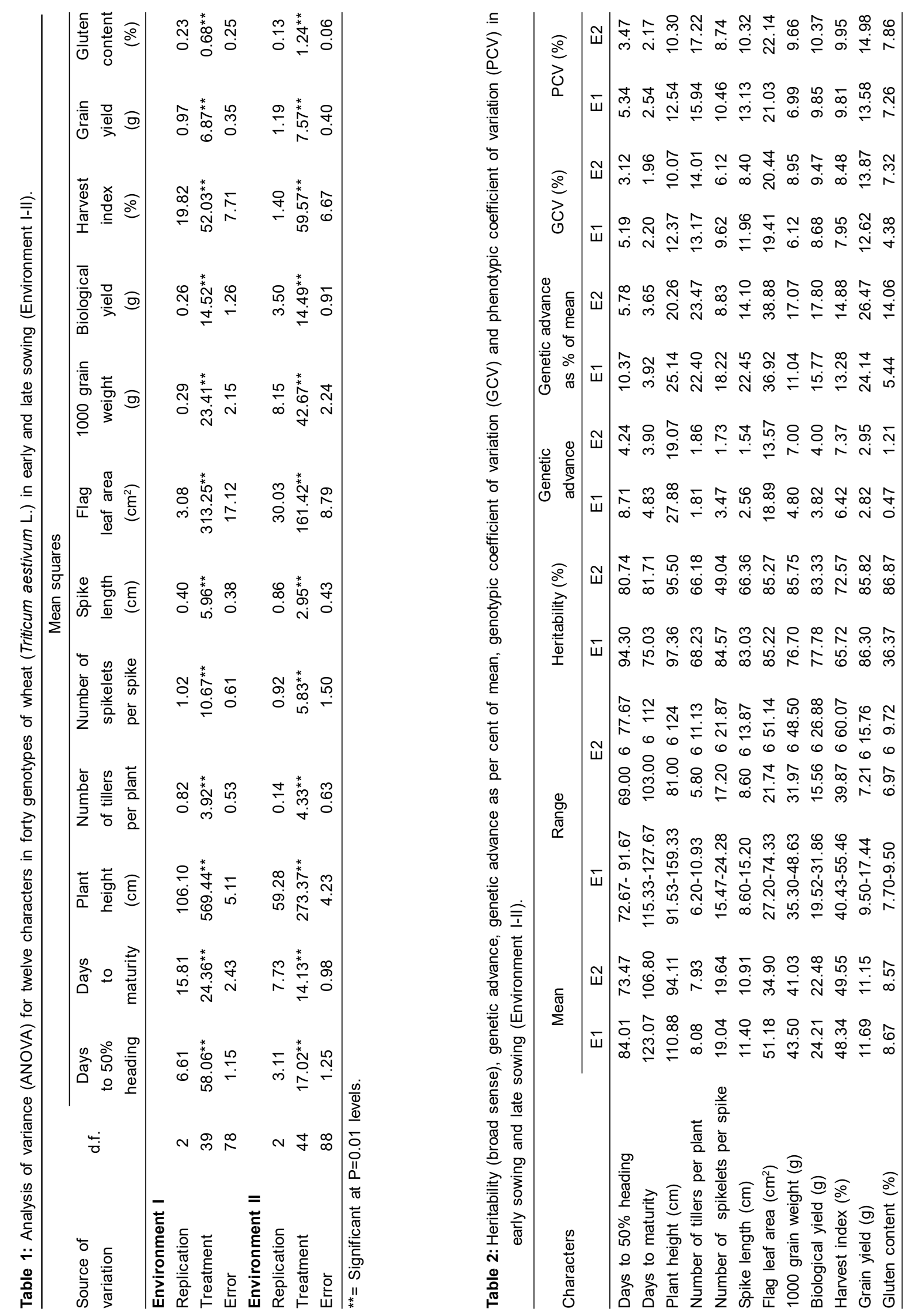

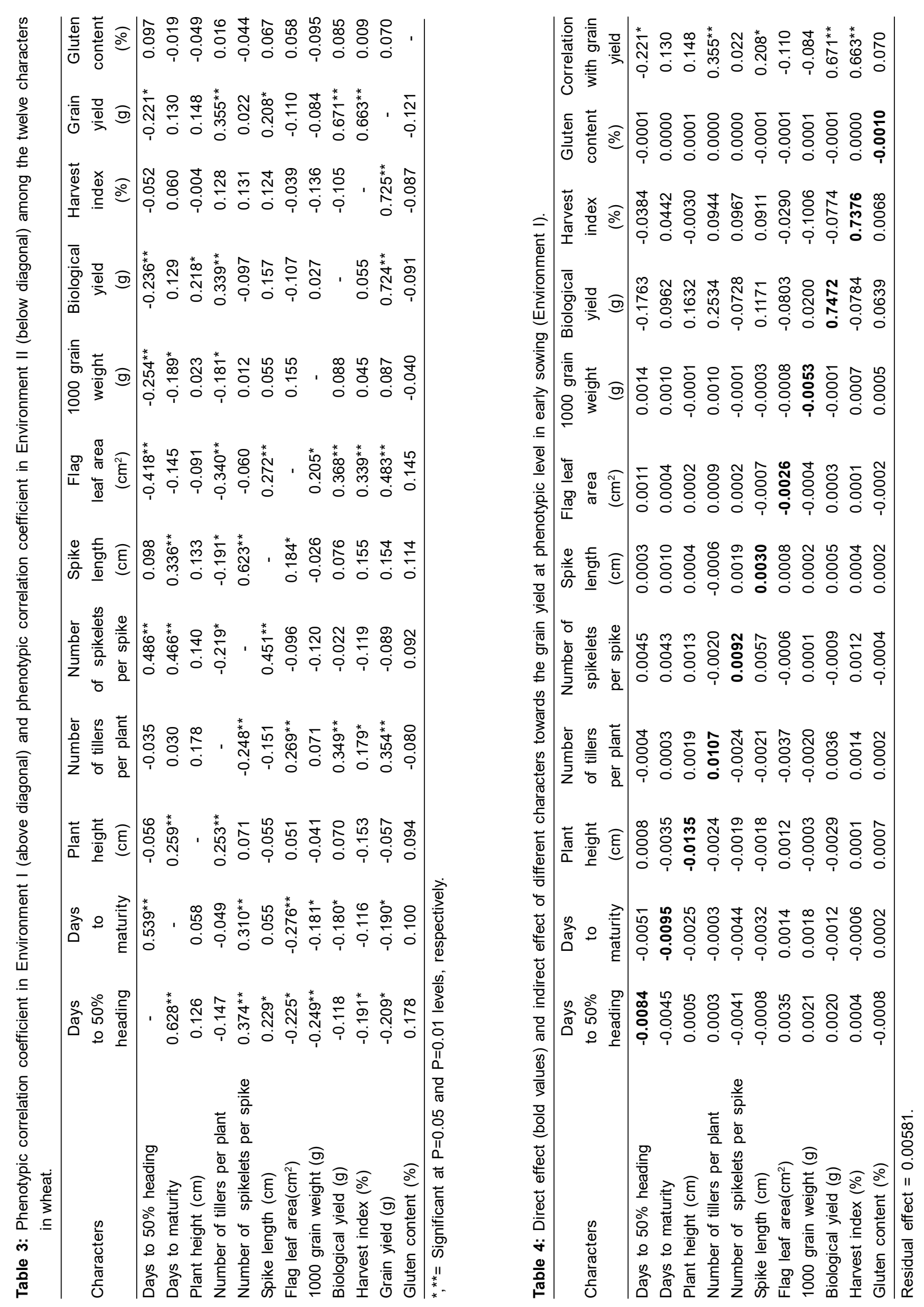

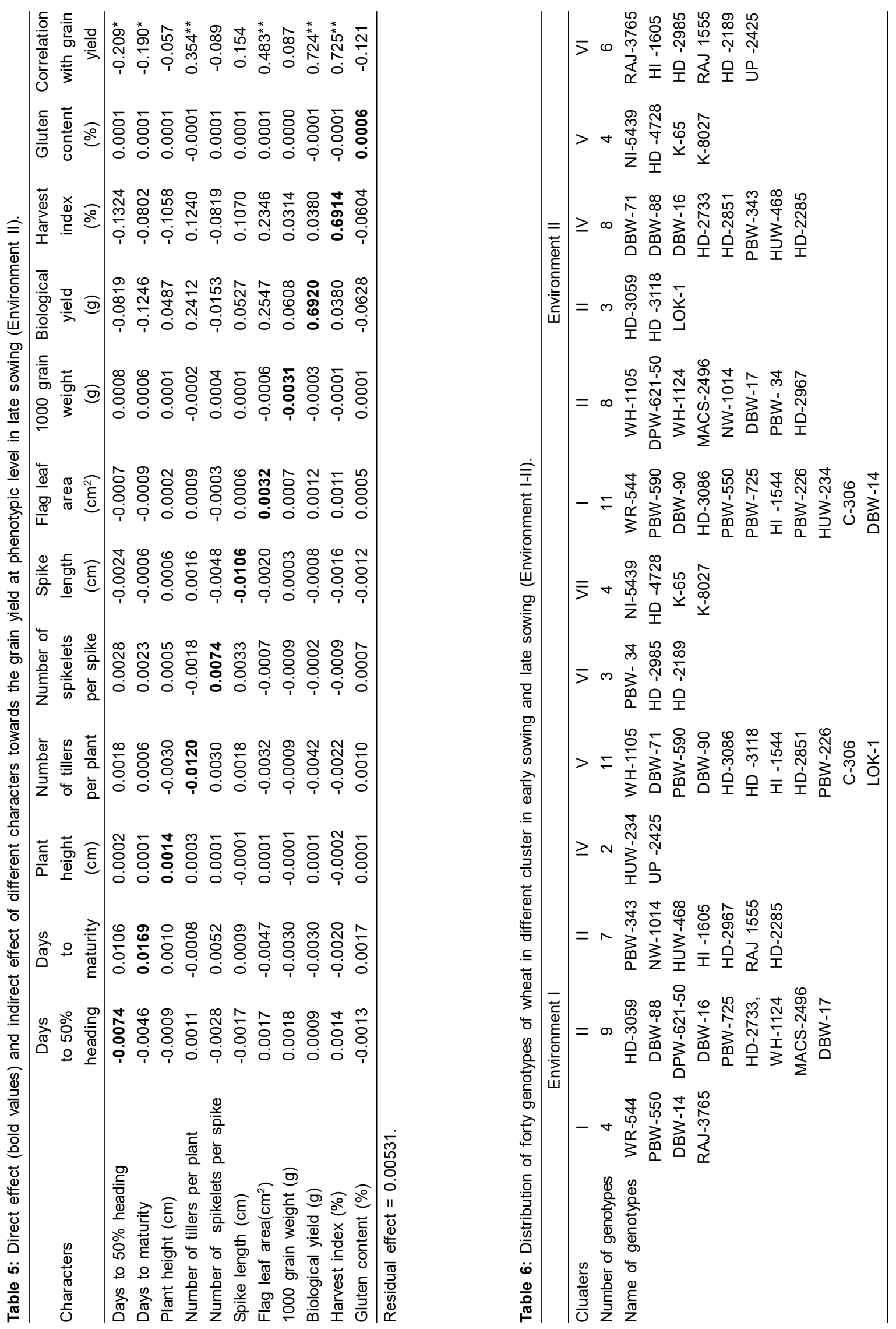
Assessment of Genetic Diversity and Character Associations for Yield and Its Traits in Bread Wheat (Triticum aestivum L.)

Table 7: Average inter and intra-cluster (bold values) distances involving forty genotypes of wheat in early sowing (Environment I).

\begin{tabular}{lccccccc}
\hline Clusters & I & II & III & IV & V & VI & VII \\
\hline I & $\mathbf{2 . 5 0 7}$ & & & & & & \\
II & 3.883 & $\mathbf{2 . 6 6 7}$ & & & & & \\
III & 3.600 & 3.006 & $\mathbf{2 . 3 1 6}$ & & & \\
IV & 5.930 & 6.199 & 5.129 & $\mathbf{1 . 4 4 2}$ & & \\
V & 2.411 & 2.560 & 3.202 & 5.684 & $\mathbf{2 . 1 6 0}$ & & \\
VI & 5.295 & 4.116 & 3.365 & 6.796 & 4.192 & $\mathbf{2 . 2 8 9}$ & $\mathbf{2 . 7 6 0}$ \\
VII & 4.979 & 3.832 & 3.836 & 5.150 & 3.848 & 4.776 & \\
\hline
\end{tabular}

Table 8: Average inter and intra-cluster (bold values) distances involving forty genotypes of wheat in late sowing (Environment II).

\begin{tabular}{lcccccc}
\hline Clusters & I & II & III & IV & V & VI \\
\hline I & $\mathbf{2 . 5 2 3}$ & & & & & \\
II & 3.935 & $\mathbf{2 . 5 9 5}$ & & & \\
III & 2.861 & 4.641 & $\mathbf{2 . 7 7 6}$ & $\mathbf{2 . 4 2 2}$ & $\mathbf{2 . 3 1 3}$ & \\
IV & 2.678 & 2.682 & 3.351 & 3.382 & 3.773 & $\mathbf{2 . 9 5 9}$ \\
V & 3.776 & 3.692 & 4.613 & 3.321 & \\
VI & 3.094 & 4.472 & 4.386 & & &
\end{tabular}

Environment I and genotypes namely HD-3059, HD-3116, LOK-1, WH-1105, DPW-621-50, WH-1124, MACS-2496, NW-1014, DBW-17, PBW- 34 and HD-2967 showed wide genetic diversity and could be used in the hybridization programme. Hybridization between the genotypes of these clusters might yield desirable segregants (Table 6-8). Similar results were also reported by Santosh et al., 2019 and Upadhyay et al. 2020.

\section{CONCLUSION}

From the present study it is concluded that the analysis of variance exhibited significant genetic variations among the genotypes for all quantitative characters studied under both the environmental conditions which may help for further selection and breeding programme which lead to transgressive segregants and genetic improvement in wheat crop. Inter and intra cluster distance indicated significant genetic diversity between and within clusters. Highest inter cluster distance was observed between clusters VI and IV in early sowing and cluster III and II in late sowing, indicating the presence of wide genetic diversity among the genotypes. The crosses between the genotypes viz., (list the clones from the clusters $\mathrm{VI}$ and $\mathrm{V}$ ) belonging to clusters pairs having large inter cluster distances may be recommended for identifying desirable recombinants in the segregating generation.

\section{ACKNOWLEDGEMENT}

I would like to thank Kisan P.G. College, Simbhaoli, Hapur (UP) and Sardar Vallabhbhai Patel University of Agriculture and Technology, Meerut (UP) for providing me research and farm facility to carry out the research work. I also thank UGC, New Delhi for provding me the financial support as RGNF.

\section{REFERENCES}

Anonymous (2020). Directorate of Economics and Statistics, Ministry of Agriculture and Farmer Welfare Government of India.
Baye, A., Berihun, B., Bantayehu, M. and Derebe, B. (2020). Genotypic and phenotypic correlation and path coefficient analysis for yield and yield related traits in advance bread wheat (Triticum aestivum L.) lines. Cogent Food Agric. 6: 1-17.

Burton, G.W. and Devane, E.H. (1953). Estimating heritability in tall fescue (Festuca arundiaceae) from replicated clonal material. Agron. J. 45: 478-481.

Chaudhary, R., Kumar, S., Singh, S., Prasad, J., Jeena, A.S. and Upreti, M.C. (2020). Study of genetic parameters and character association in wheat (Triticum aestivum L.). Int. J. Chem. Stud. 8(3): 2312-2315.

Ferede, M. and Worede, F. (2020). Variability, heritability and genetic advance analysis in bread wheat (Triticum aestivum L.) genotypes in Northwestern Ethopia. Int. J. Sust. Agric. Res. 7(2): 56-65.

Gaur, S.C. (2019). Genetic improvement through variability, heritability and genetic advance for grain yield and its contributing traits in wheat [Triticum aestivum (L.) em Thell]. Int. J. Pure App. Biosci. 7(1): 368-373.

Haydar, F.M.A., Ahamed, M.S., Siddique, A.B., Uddin, G.M., Biswas, K.L. and Alam, M.F. (2020). Estimation of genetic variability, heritability and correlation for some quantitative traits in wheat (Triticum aestivum L.). J. Bio-Sci. 28: 81-86.

Jan, N., Shakil, R. and Kashyap, S.C. (2020). Studies on inter-relationship and path analysis in wheat [Triticum aestivum (L.) em Thell] for yield and components traits. Plant Archives. 20(2): 1483-1486.

Johnson, H.W., Robinson, H.E. and Comstock, R.E. (1955). Estimates of genetic and environmental variability in soybeans. Argon J. 47: 314-318.

Joshi, A.B. and Dhawan, N.L. (1966). Genetic improvement of yield with special reference to self fertilizing crops. Indian $\mathrm{J}$. Genet. 26A: 101-113.

Khanal, D., Thapa, D.B., Dhakal, K.H., Panday, M.P. and Kandel, B.P. (2020). Correlation and path coefficient analysis of elite spring wheat lines developed for high temperature tolerance. Environ. Eco. Sci. 4(2): 56-59. 
Kumar, S., Chaudhary, A.M., Purushottam, Singh, V., Chauhan, M.P. and Yadav, R.D.S. (2019). Studies of variability, heritability and genetic advance in some quantitative characters in bread wheat (Triticum aestivum L.). J. Pharmocognosy Phytochem. 8(4): 402-404.

Kumari, M., Kumar, M.,Singh, V., Kumar, S.V. and Rathi, M. (2017). Trait association and morphological diversity in wheat (Triticum aestivum L.) genotypes. Electronic J. Plant Breed. 8(2): 534-540.

Mahalanobis, P.C. (1936). On the generalized distances in statistics. Proc. Natl. Sci. India. 2: 49-55.

Mishra, V., Sharma, A.K. and Chauhan, S. (2019). Genetic variability, heritability and genetic advance in bread wheat (Triticum aestivum L.). Int. J. Curr. Microbiol. App. Sci. 8(7): 2311-2315.

Onwueme, I.C. and Sinha, T.D. (1999). Field Crops Production in Tropical Africa. CTA Publications, Wageningen, pp. 250266.

Panse, V.G. and Sukhatme, P.V. (1969). Statistical Methods of Agricultural Workers. $2^{\text {nd }}$ Edition, ICAR Publication, New Delhi, pp., 381.

Rathod, S.T., Pole, S.P. and Gawande, S.M. (2020). Correlation and path analysis for quality and yield contributing traits in wheat (Triticum aestivum L.). Int. J. Microbiol. App. Sci. 8(6): 456-461.
Saini, P.K., Kumar, S. and Singh, S.V. (2019). Heritability and genetic advance for yield and its contributing traits in bread wheat (Triticum aestivum L.). Int. J. Chem. Stud. 7(3): 3078-3081.

Santosh, Jaiswal, J.P., Singh, A. and Gahatyari, N.C. (2019). Genetic diversity analysis in bread wheat [Triticum aestivum (L.) Em. Thell.] for yield and physiological traits. Int. J. Curr. Microbiol. App. Sci. 8(2): 3059-3068.

Upadhaya, P., Krishna, S., Thakur, P., Agarwal, N., Yadav, P., Prasad, L.C. and Mishra, V.K. (2020). Identification of genetic variability and diversity in selected wheat (Triticum aestivum $\mathrm{L}$ ) germplasm under three different dates of sowing. J. Pharmaco. Phytochem. 9(2): 82-86.

Upadhyay, K. (2020). Correlation and path coefficient analysis among yield and yield attributing traits of wheat (Triticum asetivum L.) genotypes. Archi. Agric. Environ. Sci. 5(2): 196-199.

Verma, B.P., Pathak, V.N. and Verma, O.P. (2019). Interrelationship between yield and its contributing traits in wheat (Triticum aestivum L.). Int. J. Curr. Microbiol. App. Sci. 8(02): 32093215. 